\section{Aspectos ambientais e sócio-econômicos relacionados à incidência de acidentes ofídicos no Estado do Rio de Janeiro de 1990 a 1996: uma análise exploratória}

\author{
Exploratory analysis of environmental and \\ socioeconomic factors related to snakebite \\ incidence in Rio de Janeiro from 1990 to 1996
}

Rosany Bochner 1

Claudio José Struchiner 2

\section{Introdução}

This article reports on an exploratory analysis of potential associations between snakebite incidence and environmental and socioeconomic variables in Rio de Janeiro from 1990 to 1996. Specific geographic locations in the State of Rio de Janeiro, the percentage of working children aged 10 to 14 years, illiteracy, low income, the proportion of households in agricultural areas, the proportion of crops such as beans, coffee, banana, and sugar cane, the proportion of the population working in farming activities, fallow arable land areas, natural and secondary forests, and total swine population appeared as risk factors for snakebites.

Snake Bites; Snakes; Risk Factors
A maioria dos estudos epidemiológicos sobre acidentes ofídicos realizados no Brasil nos últimos cem anos se limitaram a analisar as mesmas variáveis já apresentadas por Vital Brazil em seu Boletim para Observação de Accidente Ophidico, ou seja, sexo e idade da vítima, mês de ocorrência do acidente, local da picada, gênero da serpente, tempo decorrido entre o acidente e o atendimento e evolução 1 .

A análise da relação entre variáveis ambientais e sócio-econômicas com a incidência deste tipo de acidente poderia ser utilizada para a definição de medidas de prevenção e controle, bem como para explicar o porquê de um município apresentar mais ou menos casos que seus vizinhos. Neste sentido, este artigo se propõe a analisar, de forma exploratória, a relação entre a incidência de acidentes ofídicos no Estado do Rio de Janeiro, no período de 1990 a 1996, com algumas variáveis ambientais e sócio-econômicas, de forma a apontar possíveis fatores de risco ou mesmo de proteção.

\section{Metodologia}

Este estudo foi realizado considerando as seguintes etapas: 


\section{1a Etapa - coleta dos dados}

Primeiramente, foram coletadas as informações junto à Secretaria de Estado de Saúde do Rio de Janeiro (SES-RJ) sobre os acidentes ofídicos registrados nos anos de 1990 a 1996, distribuídos por município de ocorrência. Dados mais recentes não puderam ser disponibilizados por não se encontrarem em formato digital devido a problemas com a implantação do Sistema de Informações de Agravos de Notificação (SINAN) e do afrouxamento na exigência da obrigatoriedade da notificação, estando a distribuição do soro não mais rigorosamente condicionada ao registro dos casos 2 .

Em se tratando de um estudo exploratório, houve a preocupação na busca do maior número de variáveis ambientais e sócio-econômicas disponíveis para cada um dos municípios do Estado do Rio de Janeiro e que pudessem, de alguma forma, apresentar associação com a incidência de acidentes ofídicos.

Com relação às variáveis ambientais, trabalhamos com os dados do Centro de Informações e Dados do Rio de Janeiro (CIDE), publicados no Índice de Qualidade dos MunicípiosVerde (IQM-Verde) que, por meio da interpretação de imagens de satélite, apresenta o percentual das áreas por tipo de uso do solo (floresta ombrófila densa, formações pioneiras, vegetação secundária, área urbana, área agrícola, pastagem, área degradada, corpos d'água, afloramento rochoso e campos de altitude, não sensoriado, não classificado), segundo os municípios do Estado do Rio de Janeiro em 19943.

Utilizamos também informações da Fundação Instituto Brasileiro de Geografia e Estatística - IBGE (http://www.ibge.net/home/estatistica/indicadores/agropecuaria/Ispa/default. shtm, acessado em 30/Abr/2003) sobre a produção agrícola municipal em 1993, considerando áreas plantadas e colhidas segundo as culturas (abacate, abacaxi, alho, arroz, banana, batata-doce, batata-inglesa, café, cana-de-açúcar, caqui, coco-da-baía, feijão, figo, goiaba, laranja, limão, mamão, mandioca, manga, maracujá, melancia, melão, milho, tangerina, tomate e urucum), e as provenientes do Censo Agropecuário 1995-1996 sobre utilização das terras (lavouras permanentes e temporárias, pastagens naturais e artificiais, matas naturais e plantadas, lavouras em descanso e produtivas não utilizadas), pessoal ocupado em atividades agropecuárias (total, total de homens, homens menores de 14 anos, total de mulheres, mulhe- res menores de 14 anos), tipo de atividade do pessoal ocupado (lavoura temporária, horticultura e produtos de viveiro, lavoura permanente, pecuária, produção mista (lavoura e pecuária), silvicultura e exploração florestal), uso de maquinário e veículos na atividade rural (tratores, máquinas para plantio, máquinas para colheita, caminhões, utilitários) e criações existentes (efetivo de bovinos, suínos e galinhas, galos, frangos, frangas e pintos) (http://www.ibge. net/home/estatistica/economia/agropecuaria/censoagro/33, acessado em 07/Mai/2003).

Com relação às variáveis sócio-econômicas, trabalhamos com os dados do Instituto de Pesquisa Econômica Aplicada (IPEA) disponibilizados no CD-ROM Atlas de Desenvolvimento Humano - 1998, que apresenta, para os anos de 1970, 1980 e 1991, os indicadores de condições de vida, dos quais utilizamos indicadores de renda (renda familiar per capita média em salário mínimo de setembro de 1991, percentual de pessoas com renda insuficiente, ou seja, pessoas com renda familiar per capita abaixo de meio salário mínimo de setembro de 1991), de educação (percentual da população de 25 anos e mais com menos de 4 anos de estudo, com menos de 8 anos de estudo, com mais de 11 anos de estudo, taxa de analfabetismo da população de 15 anos e mais - percentual-, número médio de anos de estudo para a população de 25 anos e mais) e de situação da infância (percentual de crianças de 7 a 14 anos que não freqüentam a escola, defasagem escolar média - em anos - das crianças de 10 a 14 anos, percentual de crianças de 10 a 14 anos com mais de um ano de atraso escolar, percentual de crianças de 10 a 14 anos que trabalham), todos com base nos dados de 19914 .

Ainda com relação às variáveis sócio-econômicas, utilizamos também dados do CIDE publicados no CD-ROM da Economia Fluminense (Produto Interno Bruto - PIB - para os setores agropecuária, indústria, comércio, construção civil, serviços industriais de utilidade pública, transporte e comunicações, intermediação financeira, administração pública, aluguéis e prestação de serviços com referência ao ano de 1998) 5, no Índice de Qualidade dos Municípios - Carências (IQM-Carências) (carência de alfabetização dos jovens em 1996 que é dada pela expressão: 100 - (Pessoas de 15 a 24 anos com, pelo menos, 4 anos de estudo)/ (total de pessoas de 15 a 24 anos) * 100) 6 e no Índice de Qualidade dos Municípios - Necessidades habitacionais (IQM-Necessidades Habitacionais) (carên- 
cia de infra-estrutura (iluminação, abastecimento de água, instalação sanitária e destino do lixo), porcentagem de domicílios rurais) 7 .

Coletamos também variáveis demográficas como as populações de cada município do Estado do Rio de Janeiro referentes aos anos de 1990 a 1996 (http://www.tabnet.datasus.gov. br/cgi/tabcgi.exe?IBGE/cnv/poprj.def, acessado em $01 / \mathrm{Jul} / 2003$ ) e suas respectivas áreas com base no ano de 19958.

\section{2a Etapa - análise das variáveis coletadas e construção de outras}

Os dados do IQM-Verde apresentaram um percentual de área agrícola igual a zero para vários municípios que possuem alto PIB agropecuário e também grande utilização das terras com lavouras permanentes e temporárias. Estes dados têm resolução numa escala que não permite captar pequenas hortas e lavouras, locais em que a população ocupada pode se expor ao risco de acidentes, inviabilizando sua utilização em nosso estudo. Assim, decidimos desconsiderar estes dados na elaboração do nosso modelo.

Foram construídas as seguintes variáveis para cada município: coeficiente de incidência de acidentes ofídicos (número de acidentes ofídicos registrados no período de 1990 a 1996/ população residente no período de 1990 a 1996 * 100 mil), densidade demográfica em 1995 (população em 1995/área em 1995), proporção do total de pessoal ocupado em atividades agropecuárias em 1995 (total de pessoal ocupado em atividades agropecuárias em 1995/população em $1995^{*} 100$ ), taxa total de máquinas de plantio e colheita em 1995 (total de máquinas de plantio e colheita em 1995/total de pessoas ocupadas em lavouras temporárias e permanentes em 1995) e percentual PIB agropecuário. Consideramos também três variáveis do tipo binárias (dummy) para representar as fronteiras dos municípios com os Estados de São Paulo, Minas Gerais e Espírito Santo. Outras oito variáveis também do tipo dummy foram construídas para classificar cada um dos municípios em uma das oito regiões do Estado do Rio de Janeiro, consideradas pelo CIDE e pela SES-RJ, Baía da Ilha Grande, Baixadas Litorâneas, Centro-Sul Fluminense, Médio Paraíba, Metropolitana, Noroeste Fluminense, Norte Fluminense e Serrana.

\section{3ạ Etapa - seleção das variáveis que farão parte do modelo}

Consideramos apenas as áreas plantadas para os produtos cultivados em mais de $50 \%$ dos municípios. As áreas colhidas, por estarem intimamente relacionadas às áreas plantadas, foram desconsideradas.

Com relação ao pessoal ocupado em atividades agropecuárias, consideramos apenas o total sem fazer distinção entre sexo e idade, uma vez que o acidente está diretamente relacionado com a exposição a atividades agrícolas, sendo secundária as relações apresentadas por sexo e idade.

Os dados sobre utilização das terras e pessoal ocupado por tipo de atividade geram informações muito parecidas. Optamos assim pela utilização de terras por esta contemplar as áreas ocupadas com lavouras em descanso e áreas produtivas não utilizadas.

Para o uso de maquinário e veículos, consideramos apenas as máquinas para plantio e para colheita, pois tratores, caminhões e utilitários não apresentam uma relação direta com a exposição a este tipo de acidente.

Com relação aos dados sócio-econômicos, selecionamos apenas uma variável de cada conjunto de indicadores, uma vez que elas exprimem informação de mesma natureza. O percentual de pessoas com renda insuficiente foi selecionado para representar a renda, e o percentual de crianças de 10 a 14 anos que trabalham, para representar a situação da infância. Os indicadores de educação foram representados pela carência de alfabetização dos jovens, que contempla, de forma mais contundente, a precariedade educacional ao agregar, em um índice, as informações de baixa escolaridade em jovens de 15 a 24 anos.

Assim, consideramos as seguintes variáveis para fazerem parte do modelo: percentual de pessoas com renda insuficiente, percentual de crianças de 10 a 14 anos que trabalham, densidade demográfica (habitantes $/ \mathrm{km}^{2}$ ), áreas plantadas de arroz, banana, café, cana-de-açúcar, feijão, mandioca, milho e tomate, áreas ocupadas com lavouras permanentes e temporárias, com pastagens naturais e artificiais, com matas naturais e plantadas, com lavouras em descanso e áreas produtivas não utilizadas, proporção do total de pessoal ocupado em atividades agropecuárias, total de rebanhos de bovinos, de suínos, de galinhas, galos, frangos, frangas e pintos, taxa total de máquinas de plantio e colheita, carência de alfabetização dos jovens, carência de infra-estrutura, percentual do PIB agropecuário, fronteiras com São Paulo, Minas Gerais e Espírito Santo, percentual de domicílios rurais, Regiões Baía da Ilha Grande, Baixadas Litorâneas, Centro-Sul Fluminense, Médio Paraíba, Metropolitana, Noroeste Fluminense, Norte Fluminense e Serrana. 
4a Etapa - escolha do modelo a ser utilizado e aplicação do teste não paramétrico de Kruskal-Wallis para comparar as regiões do Estado do Rio de Janeiro

Pela natureza da variável resposta, número de acidentes ofídicos registrados anualmente para cada município, optamos pela utilização de um modelo de regressão múltipla de Poisson, com a aplicação do programa S-Plus, no qual:

Ln (número de eventos/pessoa tempo) = beta $0+$ beta $1 *$ variável $1+\ldots$

Ln (número de eventos) $=$ beta $0+$ beta $1 *$ variável $1+\ldots+\ln$ (pessoa tempo)

Para verificar a existência ou não de diferenças significativas entre as regiões do Estado do Rio de Janeiro no que se refere ao coeficiente de incidência de acidentes ofídicos, aplicamos o teste não paramétrico de Kruskal-Wallis e, para tanto, utilizamos o programa Statgraphics. Como o programa só fornece uma análise gráfica para comparar uma região com as demais, construímos uma matriz que indica para cada par de regiões se estas podem ser consideradas iguais ou diferentes frente à sua incidência de acidentes ofídicos 9 .

\section{5a Etapa - análise dos coeficientes} de incidência por meio de um Box-plot e representação em mapa temático

Construímos um box-plot para os coeficientes de incidência de acidentes ofídicos, de forma a obter intervalos que indicam os municípios que apresentam coeficientes considerados muito fora, fora, adjacentes ou internos. Para tanto, utilizamos os valores da mediana, 1o quartil, $3 \underline{\text { o }}$ quartil, distância interquartílica (3o quartil - 1o quartil), cerca interna superior (3o quartil $+1,5$ $x$ distância interquartílica), cerca interna inferior (1o quartil - 1,5 x distância interquartílica), cerca externa superior (cerca interna superior + 1,5 x distância interquartílica) e cerca externa inferior (cerca interna inferior - 1,5 x distância interquartílica) 10. Com os municípios assim classificados, construímos um mapa temático de forma a visualizar as áreas mais críticas para este tipo de acidente (Figura 1).

\section{Resultados}

A Tabela 1 apresenta as variáveis que são significativas para explicar a variação da incidência dos acidentes ofídicos no Estado do Rio de Janeiro, com seus respectivos coeficientes, erros padrão e valores da estatística t. Podemos observar, pelo sinal positivo do coeficiente, quais são as variáveis de risco, ou seja, aquelas que, quando crescem, aumentam a incidência do número de acidentes ofídicos. $\mathrm{O}$ sinal negativo do coeficiente indica as variáveis de proteção, ou seja, aquelas em que a incidência de acidentes diminui com seu aumento. A magnitude destes coeficientes nos indica a importância de cada uma destas variáveis no modelo quando controlada pelas demais. Assim, temos as seguintes variáveis de risco em ordem de importância: regiões Baía da Ilha Grande, Centro-Sul Fluminense, Médio Paraíba e Serrana, percentual de crianças de 10 a 14 anos que trabalham, carência de alfabetização de jovens, percentual de renda insuficiente, percentual de domicílios rurais, áreas plantadas de feijão, de café e de banana, proporção total de pessoal ocupado em atividades agropecuárias, lavouras em descanso e produtivas não utilizáveis, área plantada de cana-de-açúcar, matas naturais e plantadas e total de suínos. As variáveis de proteção em ordem de importância são as seguintes: fronteira com Espírito Santo, regiões Metropolitana, Norte Fluminense e Baixadas Litorâneas, fronteiras com São Paulo e com Minas Gerais, percentual de PIB agropecuário, taxa total de máquinas de plantio e colheita, áreas plantadas de tomate e de mandioca, lavouras permanentes e temporárias, densidade demográfica e total de bovinos.

A Tabela 2 apresenta os resultados da aplicação do teste de Kruskal-Wallis, e, sendo o pvalor menor que 0,05 , podemos concluir que existem diferenças significativas entre as regiões do Estado com relação aos coeficientes de incidência de acidentes ofídicos. Para verificarmos que regiões são diferentes das demais, construímos a Tabela 3 que informa para cada par de regiões se estas podem ser consideradas iguais ou diferentes.

A Tabela 4 apresenta a classificação de cada um dos municípios em pontos muito fora (coeficientes além das cercas externas), pontos fora (coeficientes entre as cercas internas e externas), pontos adjacentes (coeficientes entre cada um dos quartis e as cercas internas) e pontos internos (coeficientes entre os quartis).

\section{Discussão}

As regiões apresentam grande importância no que se refere aos coeficientes de incidência para acidentes ofídicos. Se por um lado as regiões Baía da Ilha Grande, Serrana, Centro-Sul Fluminense e Médio Paraíba representam risco, por outro lado as regiões Metropolitana, Norte Fluminense e das Baixadas Litorâneas repre- 


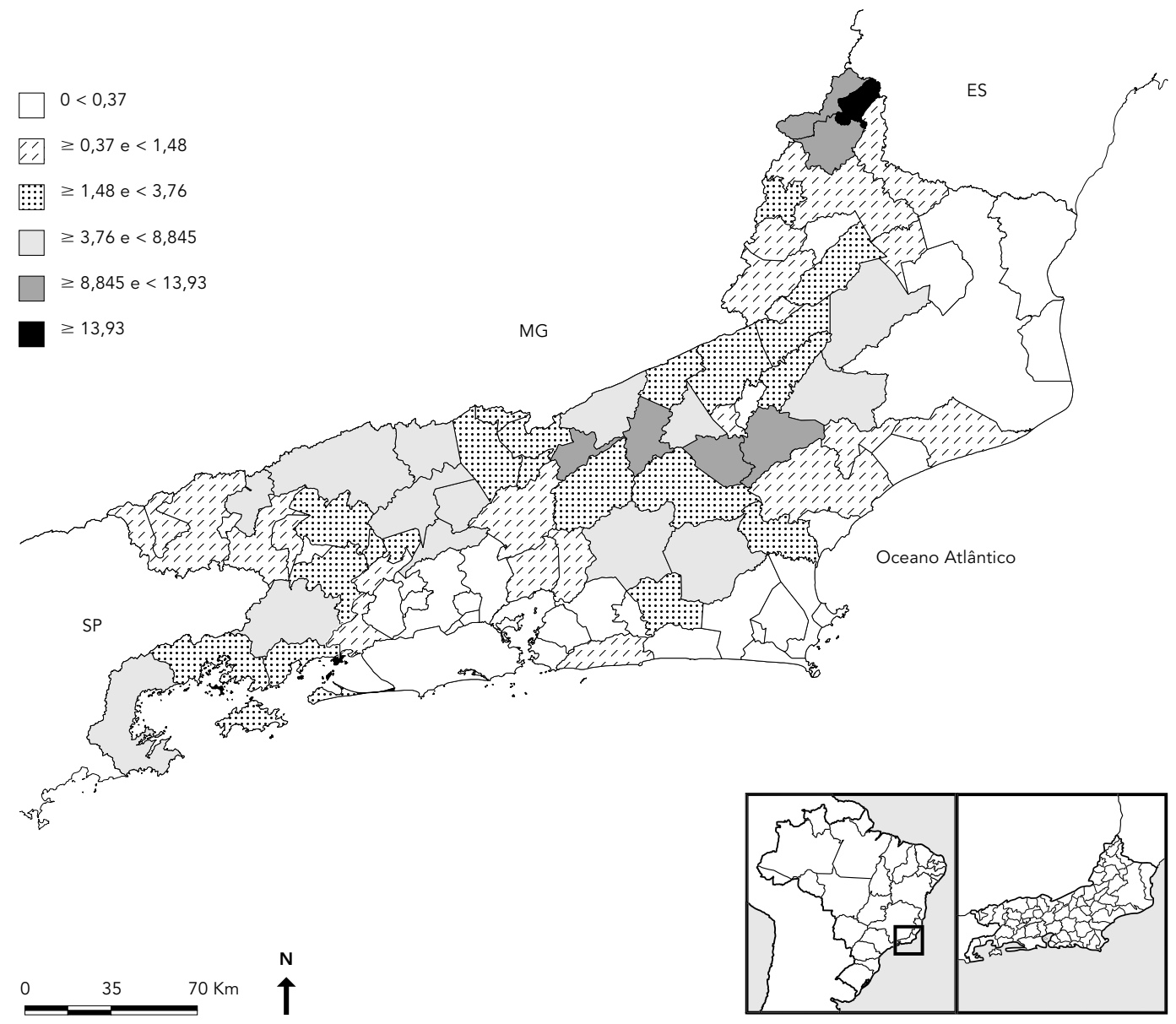

sentam proteção. A região Noroeste Fluminense não foi considerada significativa para o modelo (Tabela 1). Por meio da Tabela 3, podemos verificar que a região Metropolitana apresenta igualdade com a região Norte Fluminense e com a das Baixadas Litorâneas, diferindo das demais. Por outro lado, a região Serrana difere das regiões Metropolitana, Norte Fluminense e das Baixadas Litorâneas e não difere das demais regiões. Podemos construir assim dois grupos distintos, um com valores mais altos que são exatamente as regiões de risco e outro com valores mais baixos contendo as regiões de proteção. A não inclusão na resposta do modelo da região Noroeste Fluminense fica mais claro quando verificamos que esta região apresenta igualdade tanto com algumas regiões do grupo de proteção (Norte Fluminense e das Baixadas Litorâneas) como com todas as regiões do grupo de risco (Baía da Ilha Grande, Centro-Sul Fluminense, Médio Paraíba e Serrana).

As fronteiras com os Estados de Espírito Santo, Minas Gerais e São Paulo apresentam um coeficiente negativo, o que não era esperado, uma vez que estes Estados, com exceção de São Paulo, possuem coeficientes de incidência superiores ao do Estado do Rio de Janeiro, que é de 6,8 (Espírito Santo - 58,2, Minas Gerais 19,2 e São Paulo - 6,4). Uma possível explicação para este fato é pensarmos que as pessoas acidentadas nos municípios vizinhos a estes Estados buscam tratamento fora do Estado do Rio de Janeiro, gerando subnotificação no local de ocorrência do acidente. Contudo, observa- 
Variáveis significativas, seus coeficientes, erros padrão e respectivos valores da estatística t.

\begin{tabular}{|c|c|c|c|}
\hline Variáveis & Coeficiente & Erro padrão & Valor de $\mathrm{t}$ \\
\hline Constante & $-1.19 E+01$ & $2.21 \mathrm{E}-01$ & -53.993199 \\
\hline Total de bovinos & $-9.55 E-06$ & $2.49 \mathrm{E}-06$ & -3.829998 \\
\hline \% Domicílios rurais & $1.07 \mathrm{E}-02$ & $2.04 \mathrm{E}-03$ & 5.259155 \\
\hline Região Metropolitana & $-7.16 \mathrm{E}-01$ & $1.35 \mathrm{E}-01$ & -5.300137 \\
\hline Feijão - área plantada & $1.61 \mathrm{E}-03$ & $2.07 \mathrm{E}-04$ & 7.76558 \\
\hline Densidade demográfica & $-1.35 \mathrm{E}-04$ & 3.07E-05 & -4.384464 \\
\hline Matas naturais e plantadas & $5.47 \mathrm{E}-05$ & $5.06 \mathrm{E}-06$ & 10.811169 \\
\hline Região Centro-Sul Fluminense & $1.24 \mathrm{E}+00$ & $1.20 \mathrm{E}-01$ & 10.29847 \\
\hline Café - área plantada & 7.49E-04 & 1.35E-04 & 5.535558 \\
\hline Banana - área plantada & 3.67E-04 & $2.86 \mathrm{E}-05$ & 12.847456 \\
\hline$\%$ de Crianças de 10 a 14 anos que trabalham & 9.19E-02 & $7.42 \mathrm{E}-03$ & 12.386763 \\
\hline Mandioca - área plantada & $-2.98 \mathrm{E}-04$ & $9.99 \mathrm{E}-05$ & -2.982274 \\
\hline Região Baía da Ilha Grande & $1.58 \mathrm{E}+00$ & $1.82 \mathrm{E}-01$ & 8.680069 \\
\hline Fronteira com Espírito Santo & $-7.96 \mathrm{E}-01$ & $1.97 \mathrm{E}-01$ & -4.044515 \\
\hline Proporção total de pessoal ocupado & $2.05 \mathrm{E}-04$ & $2.30 \mathrm{E}-05$ & 8.914893 \\
\hline$\%$ de Renda insuficiente & 2.47E-02 & $3.60 \mathrm{E}-03$ & 6.849304 \\
\hline Região Serrana & $3.73 \mathrm{E}-01$ & $1.32 \mathrm{E}-01$ & 2.827865 \\
\hline Região Médio-Paraíba & 8.31E-01 & $1.44 \mathrm{E}-01$ & 5.780651 \\
\hline Total de suínos & 4.29E-05 & $8.45 \mathrm{E}-06$ & 5.077397 \\
\hline Tomate - área plantada & $-2.30 \mathrm{E}-03$ & 2.87E-04 & -8.010041 \\
\hline Carência de alfabetização de jovens & 2.97E-02 & $5.97 \mathrm{E}-03$ & 4.979388 \\
\hline \% PIB Agropecuário & $-1.09 \mathrm{E}-02$ & $3.38 \mathrm{E}-03$ & -3.228116 \\
\hline Lavouras permanentes e temporárias & $-2.22 \mathrm{E}-04$ & $3.08 \mathrm{E}-05$ & -7.188323 \\
\hline Cana-de-açúcar - área plantada & 0.000170647 & $2.49037 \mathrm{E}-05$ & 6.852255 \\
\hline Taxa total de máquinas de plantio e colheita & -0.003304255 & 0.002303605 & -1.434384 \\
\hline Lavouras em descanso e produtivas não utilizadas & 0.000187818 & 3.85583E-05 & 4.871011 \\
\hline Fronteira com São Paulo & -0.317945302 & 0.09720792 & -3.270776 \\
\hline Região Norte Fluminense & -0.672015054 & 0.1609981 & -4.174056 \\
\hline Fronteira com Minas Gerais & -0.249570712 & 0.08491348 & -2.939118 \\
\hline Região das Baixadas Litorâneas & -0.338708202 & 0.162982072 & -2.078193 \\
\hline Arroz - área plantada & $-8.85034 \mathrm{E}-05$ & 5.21977E-05 & -1.695542 \\
\hline
\end{tabular}

mos que apenas em Comendador Levy Gasparian, Quatis e Rio das Flores, que apresentam fronteira com o Estado de Minas Gerais, não existem pólos de aplicação de soro.

Segundo Ministério da Saúde/Fundação Nacional de Saúde 11, as serpentes do gênero Crotalus (cascavel) não são encontradas no Estado do Rio de Janeiro. Contudo, no período de 1990 a 1996, foram registrados 15 acidentes envolvendo este gênero de serpente, sendo que 13 ocorreram em municípios que apresentam fronteira com Minas Gerais (8 em Valença, 2 em Resende, 2 em Rio das Flores e 1 em Itatiaia) e 2 em municípios que não são fronteiriços, Magé (Região Metropolitana) e Volta Redonda (Região do Médio Paraíba). Segundo Melgarejo 12, as cascavéis começam a invadir paulatinamente as regiões Sudeste e Nordeste do país, fenô-
Tabela 2

Teste de Kruskal-Wallis para coeficientes de incidência de acidentes ofídicos no Estado do Rio de Janeiro, Brasil, no período de 1990 a 1996 por regiões do Estado.

\begin{tabular}{lcl}
\hline Regiões & Tamanho da Amostra & Média dos Postos \\
\hline Baía da llha Grande & 2 & 63,0 \\
Baixadas Litorâneas & 10 & 30,85 \\
Centro-Sul Fluminense & 10 & 57,1 \\
Metropolitana & 17 & 16,0882 \\
Médio Paraíba & 10 & 48,95 \\
Norte Fluminense & 7 & 28,9286 \\
Noroeste Fluminense & 12 & 46,5833 \\
Serrana & 13 & 60,8462 \\
\hline
\end{tabular}

Estatística do teste $=40,2691 ; \mathrm{p}$-valor $=0,00000111799$ 
Tabela 3

Comparação entre as medianas das regiões com relação ao coeficiente de incidência de acidentes ofídicos.

\begin{tabular}{|c|c|c|c|c|c|c|c|c|}
\hline & BI & BL & CS & ME & MP & NF & NO & SE \\
\hline $\mathrm{BI}$ & & Igualdade & Igualdade & Diferença & Igualdade & Igualdade & Igualdade & Igualdade \\
\hline$B L$ & Igualdade & & Diferença & Igualdade & Igualdade & Igualdade & Igualdade & Diferença \\
\hline $\mathrm{CS}$ & Igualdade & Diferença & & Diferença & Igualdade & Diferença & Igualdade & Igualdade \\
\hline ME & Diferença & Igualdade & Diferença & & Diferença & Igualdade & Diferença & Diferença \\
\hline MP & Igualdade & Igualdade & Igualdade & Diferença & & Igualdade & Igualdade & Igualdade \\
\hline$N F$ & Igualdade & Igualdade & Diferença & Igualdade & Igualdade & & Igualdade & Diferença \\
\hline NO & Igualdade & Igualdade & Igualdade & Diferença & Igualdade & Igualdade & & Igualdade \\
\hline SE & Igualdade & Diferença & Igualdade & Diferença & Igualdade & Diferença & Igualdade & \\
\hline
\end{tabular}

$\mathrm{BI}=$ Região Baía da llha Grande; BL = Região das Baixadas Litorâneas; CS = Região Centro-Sul Fluminense;

$\mathrm{ME}=$ Região Metropolitana; MP = Região Médio Paraíba; NF = Região Norte Fluminense; NO = Região Noroeste

Fluminense; SE = Região Serrana

Tabela 4

Limites do Box-plot para os coeficientes de incidência de acidentes ofídicos (x 10 mil) registrados no Estado

do Rio de Janeiro, Brasil, no período de 1990 a 1996, com os respectivos municípios pertencentes a cada região.

\begin{tabular}{|c|c|c|}
\hline Limites & Característica & Municípios \\
\hline $\begin{array}{l}\geq 13,93 \\
\geq \text { Cerca Externa Superior }\end{array}$ & Pontos Muito Fora & Varre-Sai \\
\hline $\begin{array}{l}\geq 8,845 \text { e }<13,93 \\
\geq \text { Cerca Interna Superior e } \\
<\text { Cerca Externa Superior }\end{array}$ & Pontos Fora & $\begin{array}{l}\text { Sumidouro, Bom Jardim, Trajano de Morais, São José do Vale do Rio Preto, } \\
\text { Porciúncula, Natividade }\end{array}$ \\
\hline $\begin{array}{l}\geq 3,76 \text { e }<8,845 \\
\geq 3 \text { 으 Quartil e } \\
<\text { Cerca Interna Superior }\end{array}$ & Pontos Adjacentes & $\begin{array}{l}\text { Rio Claro, Santa Maria Madalena, Duas Barras, Parati, Vassouras, Rio das Flores, } \\
\text { Cachoeiras de Macacu, Miguel Pereira, Sapucaia, São Fidélis, Silva Jardim, Valença, } \\
\text { Quatis, Paty do Alferes }\end{array}$ \\
\hline $\begin{array}{l}\geq 1,48 \text { e }<3,76 \\
\geq \text { Mediana e }<\text { 3o Quartil }\end{array}$ & Pontos Internos & $\begin{array}{l}\text { Cantagalo, Mendes, Laje do Muriaé, Carmo, Paraíba do Sul, Angra dos Reis, Areal, } \\
\text { Mangaratiba, Teresópolis, Piraí, Cambuci, Nova Friburgo, São Sebastião do Alto, } \\
\text { Três Rios, Engenheiro Paulo de Frontin, Comendador Levy Gasparian, Casimiro de } \\
\text { Abreu, Rio Bonito, Barra do Piraí, Itaocara }\end{array}$ \\
\hline $\begin{array}{l}\geq 0,37 \text { e }<1,48 \\
\geq 1 \text { 으 Quartil e }<\text { Mediana }\end{array}$ & Pontos Internos & $\begin{array}{l}\text { Conceição de Macabu, Resende, Italva, Itatiaia, Magé, Macaé, Petrópolis, Itaperuna, } \\
\text { Cordeiro, Santo Antônio de Pádua, Barra Mansa, Miracema, Paracambi, Maricá, } \\
\text { Bom Jesus do Itabapoana, Guapimirim, Itaguaí, Quissamã, Volta Redonda, Aperibé }\end{array}$ \\
\hline $\begin{array}{l}\geq-4,75 \text { e }<0,37 \\
\geq \text { Cerca Interna Inferior e } \\
<1 \text { o Quartil }\end{array}$ & Pontos Adjacentes & $\begin{array}{l}\text { Rio das Ostras, São Pedro da Aldeia, Saquarema, Cardoso Moreira, Cabo Frio, Itaboraí, } \\
\text { Campos dos Goytacazes, Niterói, Japeri, Duque de Caxias, Araruama, São João } \\
\text { da Barra, Rio de Janeiro, Arraial do Cabo, Nova Iguaçu, São Gonçalo, Queimados, } \\
\text { Belford Roxo, São João de Meriti, Nilópolis }\end{array}$ \\
\hline
\end{tabular}


meno este que vem sendo verificado no Estado do Rio de Janeiro.

Apesar da variável carência de infra-estrutura não ter sido considerada relevante, Melgarejo 12 considera como fatores de risco, para este tipo de acidente, problemas de infra-estrutura urbana, tais como moradias inapropriadas, falta de saneamento básico e coleta e disposição inadequada de lixo, que propiciam a invasão e a proliferação de ratos e outras pragas domésticas, o que tem facilitado a aproximação e a permanência de serpentes como a jararaca e a jararacuçu, trazendo com isso o ofidismo para os centros urbanos.

As variáveis sócio-econômicas relacionadas como fatores de risco, como percentual de crianças de 10 a 14 anos que trabalham, carência de alfabetização de jovens, percentual de renda insuficiente, percentual de domicílios rurais e proporção total de pessoal ocupado em atividades agropecuárias, mostram o quanto o acidente ofídico está relacionado com populações rurais de baixa renda, geralmente excluídas das políticas públicas. Talvez por esta razão, apesar destes acidentes constituírem um problema de saúde pública, eles não vêm recebendo a merecida atenção das autoridades competentes.

Com relação às culturas plantadas, por um lado, temos o feijão e a cana-de-açúcar (culturas temporárias) e o café e a banana (culturas permanentes) como fatores de risco, e, por outro lado, temos o tomate, a mandioca e o arroz (culturas temporárias) como fatores de proteção. Borges 13 , ao considerar que $20 \%$ dos acidentes ofídicos atingem mãos e antebraços, relaciona três destas culturas com atividades de risco, cortar cana, colher café e colher arroz. Segundo Garcia 14, o tomate apresentou a maior quantidade de agrotóxicos vendidos em relação à área de cultivo em 1985, 44,8kg/ha, e o Programa Nacional de Análise de Resíduos de Agrotóxicos em Alimentos (PARA), implantado pela Agência Nacional de Vigilância Sanitária (ANVISA) em julho de 2001 nos Estados de São Paulo, Paraná, Minas Gerais e Pernambuco, apresentou o tomate como a terceira cultura com maior concentração de contaminação (27\% das amostras) 15 . Estes dados nos levam a concluir que o uso de agrotóxicos pode estar inversamente relacionado à incidência destes acidentes. Contudo, apesar de Chippaux et al. 16 terem sugerido uma relação entre o aumento da utilização de adubos químicos e inseticidas com uma diminuição progressiva das capturas de serpentes, ele observou que a morbidade de acidentes ofídicos permaneceu estável nos anos considerados em seu estudo.
Lavouras em descanso e produtivas não utilizadas e matas naturais e plantadas foram associadas com uma maior incidência de acidentes. Segundo França et al. 17, as serpentes do gênero Bothrops, responsáveis por cerca de $90 \%$ dos acidentes ofídicos que ocorrem no país, habitam preferencialmente ambientes úmidos (como matas e áreas cultivadas), locais de proliferação de roedores, zonas rurais e periferia de grandes cidades. Marques et al. 18 afirmam ainda que a maioria das serpentes do gênero Bothrops vivem em áreas florestadas, com exceção das espécies neuwiedi 19 e alternatus, que vivem predominantemente em áreas abertas. Em nosso estudo, apenas $50 \%$ das ocorrências declararam o gênero ou a espécie da serpente, e destes 98,5\% eram do gênero Bothrops; 0,6\%, Crotalus; 0,4\%, Lachesis e 0,4\%, Micrurus. Das serpentes do gênero Bothrops, 27,3\% não declararam a espécie, $66,0 \%$ eram da espécie Bothrops jararaca; 6,5\%, Bothrops jararacussu e $0,2 \%$, Bothrops alternatus. Estes resultados estão de acordo com Melgarejo 12, que afirma que o Instituto Vital Brazil recebeu, em 10 anos, 11.046 jararacas, enquanto, no mesmo período, chegaram apenas 248 jararacuçus e um número semelhante de outras espécies (entre peçonhentas e não peçonhentas), o que mostra claramente a abundância desta espécie no Estado do Rio de Janeiro.

O total de suínos aparece como um fator de risco, enquanto que o total de bovinos se apresenta como um fator de proteção. Com relação aos bovinos, seria interessante separar os de produção confinada dos que vivem soltos em pastagens. Os pastos constituem um tipo de vegetação mais rasteira e, portanto, menos promissora a abrigar serpentes. É preciso estudar melhor as condições em que os suínos são criados no Estado do Rio de Janeiro, como local da criação, tipo de alimentação e seu armazenamento, uma vez que a comida pode atrair ratos, e estes, por sua vez, atraírem serpentes. Por outro lado, Soerensen 20 , quando trata dos inimigos naturais das serpentes, afirma que os porcos e até as galinhas podem, ocasionalmente, atacar as serpentes.

O percentual do PIB agropecuário aparece como um fator protetor, o que pode parecer estranho, pois o esperado seria ter mais casos nos locais onde a atividade rural é maior. Por outro lado, podemos pensar na hipótese de que, com maior produtividade, haverá maior conhecimento de medidas preventivas para este tipo de acidente ou mesmo maior utilização de maquinário. Outra possibilidade seria considerar que produtos mais rentáveis constituam fatores de proteção para a incidência destes acidentes. 
Os sete municípios que apresentaram os maiores coeficientes de incidência de acidentes ofídicos em 100 mil habitantes (Varre-Sai 19,04, Sumidouro - 13,68, Bom Jardim - 12,93, Trajano de Morais - 12,29, São José do Vale do Rio Preto - 12,10, Porciúncula - 10,68, e Natividade - 10,06) se concentram em apenas duas regiões, Noroeste Fluminense e Serrana e apresentam densidade demográfica inferior a 68 habitantes $/ \mathrm{km}^{2}$.

Para estes sete municípios, verificamos que, com exceção de Varre-Sai que só foi criado em 1993, todos os outros seis municípios apresentaram, no ano de 1991 , mais de $50 \%$ de pessoas com renda insuficiente. Os municípios de Sumidouro, Porciúncula e Natividade apresentaram as maiores porcentagens de crianças de 10 a 14 anos que trabalham, 22,7, 22,4 e 19,4, respectivamente. Os municípios de Porciúncula, Varre-Sai, Bom Jardim, São José do Vale do Rio Preto e Natividade estão entre os oito maiores produtores de café do Estado, sendo Porciúncula o maior. Os municípios de Varre-Sai, Porciúncula e Natividade estão entre os sete maiores produtores de feijão, sendo Varre-Sai o maior. Nenhum destes sete municípios apresentou produção de mandioca, cultura considerada como um fator de proteção. Os municípios de Sumidouro e de Varre-Sai apresentaram as maiores proporções de pessoal ocupado em atividades agropecuárias, 42,26 e 33,41, respectivamente. O município de Bom Jardim apresenta a maior criação de suínos do Estado. Os municípios de Sumidouro, Varre-Sai e Trajano de Morais apresentaram as maiores carências de alfabetização, 44,3, 39,3 e 35,1, respectivamente. Os municípios de Trajano de Morais, Bom Jardim, Sumidouro e São José do Vale do Rio Preto apresentam percentuais de carência de infra-estrutura superiores a $93 \%$. Os municípios de Sumidouro e de Varre-Sai apresentaram os maiores percentuais de PIB agropecuário, 52,66 e 37,47 , respectivamente.

\section{Conclusões}

Este estudo tem caráter exploratório e, por esta razão, serve apenas para apontar possíveis fatores de risco e de proteção, que mereçam ser estudados mais atentamente em futuras análises realizadas de forma mais direcionada.

As regiões podem ser divididas em dois grupos: as de maior risco (Serrana, Sul Fluminense, Noroeste Fluminense, Baía da Ilha Grande e Médio Paraíba) e as de menor risco (Metropolitana, Baixadas Litorâneas e Norte Fluminense). Um estudo que precisa ser aprofundado é o das culturas indicadas neste estudo como constituindo fatores de risco, bem como aquelas que representam algum tipo de proteção para este tipo de acidente. $\mathrm{O}$ mesmo deve ser feito com relação ao quantitativo de bovinos e de suínos em cada município, levando em consideração, além dos tipos de rebanhos, as condições em que são criados e o seu tipo de alimentação.

As notificações dos casos de acidentes ofídicos que ocorreram nos municípios que mantêm fronteiras com os Estados de São Paulo, Minas Gerais e Espírito Santo devem ser investigados nestes Estados, pois acreditamos que o atendimento destes casos possa estar sendo realizado fora do Estado do Rio de Janeiro, gerando subnotificação. Outra questão a ser considerada consiste na análise do relevo e tipo de solo destas regiões fronteiriças.

Por meio das variáveis sócio-econômicas, verificamos a relação deste tipo de acidente com populações desfavorecidas, não apenas por apresentarem elevados percentuais de renda insuficiente, mas sobretudo pela carência de alfabetização dos jovens, sugerindo a pouca educação da população mais exposta. Esta constatação é bastante significativa ao pensarmos no aumento da gravidade dos casos devido a condutas inadequadas tomadas pela população menos informada, como a utilização de torniquete, a colocação de diversas substâncias no local da picada, a ingestão de bebidas alcoólicas e a demora para buscar tratamento médico especializado. 


\section{Resumo}

Neste trabalho foram analisadas, de forma exploratória, as relações existentes entre algumas variáveis ambientais e sócio-econômicas com a incidência de acidentes ofídicos ocorridos no Estado do Rio de Janeiro, Brasil, no período de 1990 a 1996. Concluiu-se como possíveis fatores de risco as regiões Baía da Ilha Grande, Serrana, Médio Paraíba, Noroeste Fluminense e Centro-Sul Fluminense, a porcentagem de crianças de 10 a 14 anos que trabalham, a carência de alfabetização de jovens, a porcentagem de renda insuficiente, a porcentagem de domicílios rurais, áreas plantadas de feijão, café, banana e cana-de-açúcar, a taxa total de pessoal ocupado em atividades agropecuárias, as lavouras em descanso e produtivas não utilizáveis, as matas naturais e plantadas e o total de suínos.

Mordeduras de Cobras; Cobras; Fatores de Risco

\section{Referências}

1. Bochner R, Struchiner CJ. Epidemiologia dos acidentes ofídicos nos últimos 100 anos no Brasil: uma revisão. Cad Saúde Pública 2003; 19:7-16.

2. Bochner R, Struchiner CJ. Acidentes por animais peçonhentos e sistemas nacionais de informação. Cad Saúde Pública 2002; 18:735-46.

3. Fundação Centro de Informações e Dados do Rio de Janeiro. Índice de qualidade dos municípios Verde (IQM-Verde). Rio de Janeiro: Fundação Centro de Informações e Dados do Rio de Janeiro; 2000.

4. Instituto de Pesquisa Econômica Aplicada. Atlas do desenvolvimento humano no Brasil [CD-ROM]. Rio de Janeiro: Instituto de Pesquisa Econômica Aplicada/Fundação João Pinheiro/Instituto Brasileiro de Geografia e Estatística/Programa das Nações Unidas para o Desenvolvimento; 1998.

5. Fundação Centro de Informações e Dados do Rio de Janeiro. Economia fluminense [CD-ROM]. Rio de Janeiro: Fundação Centro de Informações e Dados do Rio de Janeiro; 2001.

6. Fundação Centro de Informações e Dados do Rio de Janeiro. Índice de qualidade dos municípios carências (IQM-Carências). Rio de Janeiro: Fundação Centro de Informações e Dados do Rio de Janeiro; 2001.

7. Fundação Centro de Informações e Dados do Rio de Janeiro. Índice de qualidade dos municípios necessidades habitacionais (IQM-Necessidades Habitacionais). Rio de Janeiro: Fundação Centro de Informações e Dados do Rio de Janeiro; 2001.

8. Fundação Centro de Informações e Dados do Rio de Janeiro. Anuário estatístico do Estado do Rio de Janeiro. Rio de Janeiro: Fundação Centro de Informações e Dados do Rio de Janeiro; 1995.

9. Sheskin DJ. Handbook of parametric and nonparametric statistical procedures. Boca Raton: CRC Press; 1997.

10. Tukey JW. Exploratory data analysis. Boston: Addison-Wesley; 1977.

11. Ministério da Saúde/Fundação Nacional de Saúde. Manual de diagnóstico e tratamento de aci-

\section{Colaboradores}

R. Bochner participou de todas as etapas de elaboração do artigo. C. J. Struchiner colaborou na aplicação do modelo de regressão múltipla, e no desenho de estudo.

dentes por animais peçonhentos. Brasília: Ministério da Saúde/Fundação Nacional da Saúde; 2001.

12. Melgarejo AR. Serpentes peçonhentas no Brasil. In: Cardoso JLC, França FOS, Wen FH, Málaque CMS, Haddad Jr. V, organizadores. Animais peçonhentos no Brasil: biologia, clínica e terapêutica dos acidentes. São Paulo: Sarvier Editora; 2003. p. 33-61.

13. Borges RC. Serpentes peçonhentas brasileiras: manual de identificação e procedimentos em caso de acidentes. São Paulo: Atheneu; 2001.

14. Garcia EG. Segurança e saúde no trabalho rural: a questão dos agrotóxicos. Brasília: Centro Brasileiro de Pesquisa em Segurança, Saúde e Meio Ambiente de Trabalho; 2001.

15. Conselho Nacional de Segurança Química. Perfil nacional da gestão de substâncias químicas. Brasília: Ministério do Meio Ambiente; 2003.

16. Chippaux J-P, Bressy C. L'endémie ophidienne des plantations de Côte-d'Ivoire. Bull Soc Pathol Exot 1981; 74:458-67.

17. França FOS, Fan HW. Acidente botrópico. In: Schvartsman S, organizador. Plantas venenosas e animais peçonhentos. São Paulo: Sarvier Editora; 1992. p. 149-60.

18. Marques AO, Sazima I. História Natural das Serpentes. In: Cardoso JLC, França FOS, Wen FH, Málaque CMS, Haddad Jr. V, organizadores. Animais peçonhentos no Brasil: biologia, clínica e terapêutica dos acidentes. São Paulo: Sarvier Editora; 2003. p. 62-71.

19. Borges RC, Araujo AFB. Seleção de hábitat em duas espécies de jararaca (Bothrops moojeni Hoge e B. neuwiedi Wagler) (Serpentes, Viperidae). Revista Brasileira de Biologia 1998; 58:591-601.

20. Soerensen B. Acidentes por animais peçonhentos: reconhecimento, clínica e tratamento. São Paulo: Atheneu; 2000.

Recebido em 09/Set/2003

Versão final reapresentada em 09/Fev/2004

Aprovado 01/Mar/2004 